\title{
Opportunities and Challenges of Honey and Bees Wax Production in Ethiopia: A Systematic Review
}

\author{
Addisu Tadesse \\ Raya University, Department of environmental and natural resource economics
}

\begin{abstract}
Beekeeping is a widely practiced economic activity that has been practiced for centuries. Ethiopia is a leading honey producer in Africa with a total of around $24 \%$ of total production in the continent or nearly 44,000 tons of honey and one of the ten largest honey producing countries by contributing roughly $2.4 \%$ of total honey production in the world. The major honey and beeswax producing regions in Ethiopia are Oromia (41\%), SNNPR (22\%), Amhara (21\%) and Tigray (5\%) i.e. around 90\% of honey and beeswax is produced by four major regions of the country. The possibility of integration with other economic activities, its behavior of friendliness, and its ease to do could be seen as the opportunities in this economic activity. Farmers' reluctance to new invention, poor marketing linkage whether to local customers or foreign demand, poor infrastructure in the country, and unavailability of storage facilities and others are major challenges encountered.
\end{abstract}

Keywords: honeybee, honey, beeswax, hives

DOI: $10.7176 /$ ALST/72-04

Publication date:March $31^{\text {st }} 2019$

\section{Introduction}

Beekeeping has been practiced for centuries and about 1.9 million farm households involve in bee keeping and there are nearly 10 million bee colonies and it is important component of agriculture in Ethiopia (Fenet and Alemayehu, 2016). According to Tessega, 2009 Though it is difficult to exactly put a time reference when beekeeping was started in Ethiopia, it may date 5000 years back and the Hieroglyphs of ancient Egypt refers to Abyssinia (the former name of Ethiopia) as the source of honey and beeswax (Seid and Solomon, 2015). No country in the world has such a long tradition of beekeeping than Ethiopia (Serda et al, 2015).

Beekeeping is an environmentally friendly nonfarm economic activity which has tremendous contribution for the society and national economy. Ethiopia has a huge natural resource base for honey and bees wax production and a well-established economic activity all over the country traditionally (Seid and Solomon, 2015).

The wide climatic and topographic variability have endowed Ethiopia with diverse and unique flowering plant that is highly suitable for sustaining a large number of bee colonies and the long established practice of beekeeping (Debele et al, 2013).

Ethiopia is a leading honey producer in Africa with a total of around $24 \%$ of total production in the continent or nearly 44,000 tons of honey and one of the ten largest honey producing countries by contributing roughly $2.4 \%$ of total honey production in the world. Moreover, the country is $1^{\text {st }}$ in bee colony in Africa and the $4^{\text {th }}$ bee wax producer in the world (Fenet and Alemayehu, 2016).

Ethiopia has the potential to produce 500,000 tons and 50,000 tons of honey and beeswax per annum respectively. But, currently production is limited to 43,000-44,000 tons of honey and 3,000 tons of beeswax. One of the typical factors for this low honey and beeswax productivity is traditional hives made by farmers (Teklu and Dinku, 2016).

From this total production around $95 \%$ of the product is produced traditionally. The main products of the beekeeping industry are honey and wax (Solomon, 2016). Honey is almost exclusively consumed locally especially to make mead, local alcoholic drink made by fermenting honey with water i.e. Tej. While a considerable proportion of wax is exported. Traditional hives are the mainstay of honey production until recently, but they are backward, time-consuming to construct and give low yields compared to the modern way of production (Abebe et al, 2009).

This economic activity contributes to the income of the households and the national economy in two ways; directly and indirectly. The direct contribution of beekeeping which is the economic aspect includes the value of the outputs produced such as honey, beeswax, queen and bee colonies. And the products especially beeswax are also useful as an industrial input in the making of cosmetics and medicine (Fenet and Alemayehu, 2016). The second and important contribution is in the form of externality. Indirectly beekeeping is important in plant pollination and thereby conserves the natural environment, though little even no recognition is given especially in Ethiopia.

Beeswax is one of the most valuable bee products and it is also one of the oldest beehive products used by mankind. It is important inputs for the development of new products in various fields such as cosmetics, foods, pharmaceuticals, engineering and industries. Specifically, in the cosmetics industry it is used in the manufacturing of chap sticks, hand and face creams, lipsticks and depilatory wax and many other uses 
(Gemechis, 2014).

The major honey and beeswax producing regions in Ethiopia are Oromia (41\%), SNNPR (22\%), Amhara $(21 \%)$ and Tigray (5\%) i.e. around $90 \%$ of honey and beeswax is produced by four major regions of the country. however, the country is suffering from the ecological degradation of its natural resources and this means the basis for any honey production is threatened and affected (Teklu and Dinku, 2016).

Despite its long history of being practiced, beekeeping in Ethiopia is still an undeveloped sector of agriculture. The knowledge and skill of honey and beeswax production of Ethiopian farmers is still very traditional and the benefit from this economic activity to the farmers, traders, exporters and even for the national economy is relatively low (Seid and Solomon, 2015).

\section{Methods of beekeeping and harvest season}

Currently in Ethiopia beekeeping is practiced using three types of hives based on the level of technological advancement; these are traditional hives, transitional hives, and modern hives. There are around $4-10$ million hives all over the country of which about $95 \%$ are traditional, $4.5 \%$ are transitional, and the remaining $0.2 \%$ are of modern types (Seid and Solomon, 2015).

The detection of honey maturity or identification of honey harvesting season is different based on the experiences they develop among the traditional bee keepers in the country. Different techniques that bee keepers applied to identify honey season are: smelling of honey, end of flowering season, accumulation of bees around the entrance of hives, and weighing of the hive. Some beekeepers identify honey season by inserting a thin sized stick in to the hive. If there is honey, the stick comes back with the honey strips. This method of indicators could not be efficient in identification of honey from brood by weighing and it is also impossible to identify externally whether the honey has ripened or not. But in the case of movable comb and frame hive the maturity of honey and pure honey can be easily observed (Kebede et al, 2012).

In Ethiopia, there are generally two harvesting seasons of honey and beeswax: the major harvesting season runs from October to November and the second season lasts from April to June. Moreover, there are many small harvesting periods which depend on the type of flowering plants and rainfall patterns in different agro ecologies of the country, which experienced beekeepers and local people easily associate the harvesting season with the botanical origin of honey in their locality (Sisay, 2015).

\section{Opportunities of honey and bees wax production in Ethiopia}

As mentioned earlier this economic activity is a friendly activity with the environment i.e. it does not disturb the ecological balance of the environment just like that of animal husbandry and agriculture. Instead it can be integrated with that of agriculture and animal husbandry especially in rural part of Ethiopia (Seid and Solomon, 2015). Therefore, the possibility of integration with other economic activities, its behavior of friendliness, and its ease to do could be seen as one of the opportunities in this economic activity. Especially today since Ethiopia involved in huge conservation of natural resources work starting from the first GTP period and the mutuality behavior of this economic activity with natural resource conservation could also being seen as an opportunity. Since Ethiopia is located in the tropics it has a wide Varity of fauna resource and rich in a diversified weather condition which is suitable for beekeeping. Availability of potential flowering plants due to varying weather conditions, availability of sustainable water resources, and suitable weather conditions for the production of honey and beeswax is the other possible opportunity.

The existence of a number of local beehives and bee colonies in the country coupled with suitable agro ecological zone and environment could be the other opportunity for honey and beeswax production.

The production of modern low cost hives using locally available materials and currently the government is giving high emphasis towards this economic activity via the introduction of new technologies and giving training programmes to the beekeeper small holder farmers around rural areas. The government also highly supportive to the honey and beeswax producers to link them with local carpenters who produce modern bee hives and creating market link towards the final consumers even to the foreign market.

The other possible opportunity is the rising demand for honey and beeswax production for domestic consumption and export by different customers and institutions are also other blessings for beekeeping in the country.

\section{Challenges of honey and beeswax production in Ethiopia}

Some scholars like (Teklu and Dinku, 2016) and (Haftu and Gezu, 2014) suggest that farmer's keen interest towards the adoption of improved technologies is one of the opportunities but in my view Ethiopian farmers are relatively reluctant to new inventions so that it may be regarded as one of the challenges rather than opportunities.

The other problems in the production of honey and beeswax are poor marketing linkage whether to local customers or foreign demand, poor infrastructure in the country, and unavailability of storage facilities and 
others. According to (Kebede et al, 2012) lack of knowledge i.e. technological backwardness of the production system, bee pests and predators are also major problems in the production of honey and beeswax in the country. Ants, wax moth, honey badger, monkey, small hive beetles, lizards, spider, bee lice, and bee eater birds are some of the most harmful pests (Kebede et al, 2012).

According to (Seid and Solomon, 2014) poor pre and post- harvest management, poor marketing infrastructure, lack of smallholders access to finance, poor quality of honey and beeswax produced, lack of appropriate information, and absence of organized market channels are among the challenges of honey production.

The existence of poisonous plants could also be one of the challenges of beekeeping sub sector in the country. These plants whose nectar or pollen is toxic to the bees themselves, and those in which the honey produced from their nectar are toxic and deadliest to humans; this in turn become a challenge in decreasing demand of the products (Kebede et al, 2012).

Lack of bee forage especially to the dry lands of the country could be also one of the challenges of beekeeping. Moreover, inflated costs of improved inputs are also unaffordable and mentioned as constraints to the beekeeping business. Drought or water scarcity could also be one of the major challenges in beekeeping sector especially Qolla areas of the country. On top of this poor extension services is a challenge facing the beekeepers in the country.

The other big problem in this sub sector is environmental pollution especially in developing countries due to global pollution and the existence of pesticides and herbicides on the flowering plants (Marie-Pierre chauzat and Jean- Paul Faucon, 2007).

\section{Reference}

Chala K. Taye T. and Kebede D. (2011). Quality evaluation of honey produced in Gomma District of South Western Ethiopia. Livestock Research for Rural Development 23(9).

Marie P. C. and Jean P. F. (2007). Pesticide residues in beeswax samples collected from honey bee colonies.

Seid G. and Solomon L. (2015) review of beekeeping activities, opportunities, challenges and marketing in Ethiopia

Serda B, Zewudu T, Dereje M, Aman M (2015) Beekeeping Practices, Production Potential and Challenges of Bee Keeping among Beekeepers in Haramaya District, Eastern Ethiopia. J Veterinar Sci Technol 6:25 ${ }^{\mathrm{ii}} 5$. doi:10.4172/2157-7579.1000255

Teklu G. and Dinku N. "honeybee production system, challenges and opportunities in selected districts of Gedeo zone, southern nation, nationalities and peoples regional state, Ethiopia" international journal of research granthaalayah, vol. 4, no. 4 (2016): 49-63. 